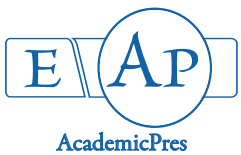

Isah T and Singh S (2021)

Notulae Scientia Biologicae

Volume 13, Issue 4, Article number 11052

DOI: $10.15835 / \mathrm{nsb} 13411052$

Research Article

\title{
Influence of plant growth regulators on morphogenic response, biomass and camptothecin production in the callus cultures of Chonemorpha fragrans (moon) Alston
}

\author{
Tasiu ISAH*, Shruti SINGH \\ Hamdard University, Department of Botany, School of Chemical and Life Sciences, New Delhi-110 062, \\ India; taasmore@yahoo.co.uk ("correspondingauthor);sakhoon2014@gmail.com
}

\begin{abstract}
In vitro morphogenic response of mature seed embryo-derived callus cultures of Chonemorpha fragrans was studied using solid and liquid Murashige and Skoog medium amended with cytokinins or their combinations with naphthalene acetic acid at $0.5 \mathrm{mg} \mathrm{L}^{-1}$. The plant growth regulators (PGRs) combination and concentrations tested could not stimulate organogenesis after three subcultivations of the callus cultures on the same PGRs-amended solid medium and when cultivated in the liquid but, formation of morphogenic callus was observed. Evaluation of biomass and camptothecin production showed that the PGRs influenced biomass and CPT yield of the callus cultures. The alkaloid yield of various explants of 3-4 weeks old axenic seedlings was higher in roots $(0.019 \%$ CPT) followed by mature seed embryos $(0.0053 \%)$, cotyledons (0.0039\%), hypocotyls (0.0024\%) and leaves $(0.0017 \%)$, and no significant difference was observed in yield of CPT from callus induced from the various explants. Camptothecin yield of morphogenic callus cultures cultivated in liquid medium was lower than that of solid due to extracellular leaching effect of the alkaloid. Amount of synthesized CPT in the callus cultures also varied with PGR type and concentration amended in the cultivation medium, and was association with biomass production. Results of the present study suggest that callus cultures offer alternative tissue source for in vitro CPT yield enhancement through biotechnological approaches, with application in the large-scale production of the alkaloid to conserve the ever-decimated natural population of the medicinal woody climber for CPT.
\end{abstract}

Keywords: alkaloid; camptothecin; medicinal plants; morphogenic callus; phytochemicals; plant growth regulators

Abbreviations: ANOVA-analysis of variance; MS-Murashige and Skoog medium; BAP-N ${ }^{6}$ benzylaminopurine; PGRs-plant growth regulators; TDZ-thidiazuron; Kin-kinetin; NAA-naphthalene acetic acid; IAA-indole acetic acid; IBA-indole butyric acid; 2,4-D-2,4-dichlorophenoxy acetic acid; CPTcamptothecin; SE-somatic embryogenesis

Received: 16 August 2021. Received in revised form: 29 Sep 2021. Accepted: 20 Oct 2021. Published online: 03 Nov 2021.

From Volume 13, Issue 1, 2021, Notulae Scientia Biologicae journal uses article numbers in place of the traditional method of continuous pagination through the volume. The journal will continue to appear quarterly, as before, with four annual numbers. 


\section{Introduction}

Chonemorpha fragrans is an evergreen laticiferous and endangered woody perennial vine of the family Apocynaceae endemic in its distributions (Khan et al., 2005). Its medicinal value was recognized and research on phytochemicals extracted from the species showed bioactivities (Clarance et al., 2019). Among the phytochemicals include chonemorphine, b-sitosterol, taraxasterol and many steroidal alkaloids (Banerji and Chatterji, 1973; Rastogi and Mehrotra, 1993; Kulkarni et al., 2010). Camptothecin (CPT), a monoterpene indole alkaloid was reported from leaf-derived callus cultures, the root and stem bark and in vitro regenerated shoots of $C$. fragrans (Kulkarni and Malpathak, 2006; Kulkarni et al., 2010). Due to slow growth of this woody climber that needs several years to reach maturity coupled with rare distribution, application of plant cell, tissue and organ culture (PCTOC) techniques offer alternative strategies for the production of CPT and other phytochemicals isolated from the species (Banerji and Chatterji, 1973; Rastogi and Mehrotra, 1993; Kedari and Malpathak, 2014). The technology can be deployed to conserve the ever-decimated natural population of $C$. fragrans as yield of the alkaloid is very low. Extensive use of $C$. fragrans in traditional systems of medicine coupled with many phytochemicals it produces calls for alternative strategies for its rapid clonal multiplication to meet demand of CPT raw material supply for anticancer drugs production by the pharmaceutical industry. However, application of PCTOC techniques, particularly influence of plant growth regulators (PGRs) in production of the alkaloid is yet unexplored in $C$. fragrans.

In previous studies, efforts were made in evaluating CPT yield from natural sources of the alkaloid for the development of in vitro production systems, so as to mitigate exploitation of its natural sources (Liu and Adams, 1996; Kai et al., 2015). However, such studies are few in the in vitro cultures of C. fragrans. In the earlier reported in vitro studies of the woody climber, Kulkarni and Malpathak (2006) developed simple method for clonal multiplication of the species on Murashige and Skoog (1962) medium (MS) amended with $\mathrm{N}^{6}$-benzylaminopurine (BAP), and micro shoots rooted using indole 3-butyric acid (IBA) at $100 \%$ efficiency. Direct plant regeneration system was achieved via axillary bud proliferation along with rooting of micro shoot on solid MS medium (Nishitha et al., 2006). In the study, shoot and root formation were achieved using medium amended with BAP and IBA concentrations, and addition of silver nitrate improved the in vitro morphogenesis parameters. Kedari and Malpathak (2014) developed transformed hairy roots from leaf and callus cultures of $C$. fragrans using Agrobacterium rhizogene strains with up to $45 \%$ transformation frequency. In recent micropropagation experiment using nodal segment explants of $C$. fragrans, explants pretreatment, culture media strength and PGRs amended, carbon source type and concentrations, and photoperiodic incubation influenced its clonal propagation efficiency (Isah and Umar, 2018). However, the effect of PGRs on CPT production and in vitro morphogenic response of callus derived from seed embryos and various explants of $C$. fragrans is yet unreported, given the application indirect plant regeneration offers in developing high CPT-producing transgenics. Further, because juvenile explants are more responsive to in vitro morphogenesis in plants (von Aderkas and Bonga, 2000) and difficulty in obtaining the most juvenile explant of the species (zygotic embryo) in a season, the present experiment evaluated in vitro morphogenic response of C. fragrans callus cultures obtained from mature seed embryos. It was carried out through cultivation of the callus cultures using solid and liquid MS medium amended with concentrations of PGRs. Camptothecin content in the various explants of 3-4-week-old axenic seedlings and seed embryo axes, resultant callus induced from the explants, and influence of PGRs on production of biomass and alkaloid from seed embryo-derived callus cultures were also analyzed. 


\section{Materials and Methods}

\section{Seeds collection and cultures establishment}

Authenticated seed samples of $C$. fragrans were obtained from Indian Institute of Horticultural Research (IIHR) Bangalore, India during March 2013. The seeds were kept in cetrimide solution for 20 minutes before it was subjected to washing under jet of running tap water for 30 minutes. Later, they were surface sterilized under laminar airflow hood chamber using $70 \%$ ethanol for five minutes, followed by rinses with sterile distilled water 2-3 times. The seeds were then treated further with freshly prepared $0.1 \%$ mercuric chloride solution for 2-3 minutes, rinsed with sterile distilled water 2-3 times and allowed to partially dry up for few minutes to avoid possible cultures contamination. Some of the seeds were subjected to early seedling recovery treatments that involved overnight soaking of the seeds in sterile distilled water (Isah and Mujib, 2015a).

The experiments were carried out in triplicate sets using MS medium that contained 3\% sucrose and solidified with 0.8\% Agar (Agar Agar Microbiology Mumbai, India) or in liquid form. Media pH was adjusted to 5.6-5.8 using $1 \mathrm{~N} \mathrm{NaOH}$ or $\mathrm{HCl}$ before autoclaved at $121{ }^{\circ} \mathrm{C}$ for 21 minutes. All of the cultures were maintained under 12 hrs day/light photoperiod provided by cool fluorescent tubes (Phillips India) having photon flux density of $40 \mathrm{~W}, 50 \mu \mathrm{mol} \mathrm{m} \mathrm{s}^{-1}$ and culture room conditions of $25 \pm 2{ }^{\circ} \mathrm{C}$ temperatures with relative humidity of $50-70 \%$.

\section{Biomass evaluation}

Callus induced from seed embryos and other explants were maintained on solid MS medium amended with 2,4-D $\left(3.0 \mathrm{mg} \mathrm{L}^{-1}\right)$ by regular subculture after every three weeks. For evaluation of the morphogenic/organogenesis response of the seed embryo-derived callus cultures and influence of PGRs on biomass production, effects of BAP, TDZ or Kin at $0.5,1.0,2.0,3.0,4.0 \mathrm{mg} \mathrm{L}^{-1}$ treatments were tested. Callus cultures were cultivated on medium supplemented with the various concentrations and when in combination with NAA $\left(0.5 \mathrm{mg} \mathrm{L}^{-1}\right)$. For each subculture cycle of the callus cultures using solid or in liquid medium cultivation systems, callus samples were harvested, the weight taken in fresh form and after dried to constant mass in an oven at $70{ }^{\circ} \mathrm{C}$. In the case of liquid medium cultivation, callus masses were inoculated into volume of autoclaved liquid medium contained in $50 \mathrm{~mL}$ capacity conical flasks, and the cultures kept on orbital shaker operated at $20 \mathrm{rpm}$ for $12 \mathrm{~h} /$ day. Fresh and absolute biomass were calculated from the relationship of callus fresh to dried weight (Isah, 2017).

\section{CPT evaluation and statistical analysis}

Extraction of CPT from dried callus cultures of $C$. fragrans and culture medium, and high-performance thin layer chromatographic (HPTLC) analysis of the extracts were carried out as described in the recent (Isah, 2019; Isah and Umar, 2019), modified in Zafar et al. (2020) and Mujib et al. (2020). CPT yield of the tissues and culture medium were evaluated using standard curve that had a linear regression line equation and expressed in percentages for tissues used without organogenesis study and in $\mathrm{mg} / \mathrm{g}$ calli DW or $\mathrm{mg} / \mathrm{mL}$ medium for others obtained from organogenesis study (experiments carried out at different times). Experiments were performed in triplicate sets of eight replicates (in the case of in vitro morphogenesis) while HPTL thrice, and obtained data analyzed using SPSS var. 21 (USA.). Significant differences between the treatments were assessed by analysis of variance (ANOVA) followed by Tukey's range test at $<0.05 \%$, and the results expressed as mean \pm standard error of the replicated experiments. 


\section{Results and Discussion}

\section{In vitro morphogenesis}

Cultures establishment for morphogenesis experiments

In the present study and based on previous experience in good callus initiation achieved with another CPT-producing woody species using 2,4-dichlorophenoxy acetic acid (2,4-D) +BAP $\left(3.0+0.5 \mathrm{mg} \mathrm{L}^{-1}\right)$ (Isah and Umar, 2019), callus initiation was achieved with mature seed embryos and explants of 3-4 weeks old axenic seedlings (Figure $1 \mathrm{~d}-\mathrm{j}$ ), and with most of the explants, the induction observed within second week of culture at differential frequency and intensity. Formation of the callus was more and earlier in the cultured seed embryos followed by cotyledons, leaves, hypocotyls and root explants and within 4-6 weeks of cultivation, most of the explants transformed into white friable callus of faster biomass accumulation (Figure 1k). In the course of maintaining the induced callus cultures (through regular subculture), formation and leaching of latex into cultivation medium that resulted in callus browning and necrosis occasionally occurred (Figure 1x). Such brownish callus cultures (Figure 1x) remained brown and non-morphogenic over several subcultures. However, addition of ascorbic acid $\left(0.5 \mathrm{mg} \mathrm{L}^{-1}\right)$ overcame the condition in most of the cultures in subsequent cultivation duration.

\section{Callus morphogenic response}

In vitro morphogenesis offers potentials for study of plants trans differentiation events, based on biosynthetic capacity to produce tissues and organs with application in the production of high-quality and disease-free plants and phytochemicals (Isah, 2015a; Espinosa-Leal et al., 2018). The system involves formation of meristemoids from single or globular mass of cells to produce organized structures such as somatic embryos, shoot or root primordium, and has been achieved with many plant species (Isah, 2015a). In the case of in vitro morphogenesis that involves a woody species, explant juvenility plays key role in the morphogenic response, and only possible with many species when a juvenile is used (von Adekas and Bonga, 2000). In the present study, the indirect morphogenic response of $C$. fragrans mature seed embryo-derived callus cultures were evaluated using solid or liquid medium cultivation supplemented with cytokinins and their combinations with naphthalene acetic acid (NAA) at lower levels. Generally, it is regarded that formation of callus opens up cellular reprogramming developmental events potential, which in turn, is determined by cultural condition for a successful organogenesis or somatic embryogenesis (Feher, 2019). Callus cultures derived from the zygotic embryo explants were cultivated on MS medium supplemented with cytokinins or their combinations with NAA at lower levels; for the morphogenic effects of BAP, TDZ or Kin on the callus cultures, callus was cultivated on MS medium supplemented with the various concentrations or when in combination with NAA $\left(0.5 \mathrm{mg} \mathrm{L}^{-1}\right)$. The seed embryo-derived callus cultivation resulted in many callus morphologies from friable, compact to nodular-green; most of the cytokinins stimulated pigmentation at variable intensity without organogenesis, with BAP as the most efficient over TDZ and Kin (Figure 11-o: p-s). However, the green pigmentation showed increased intensity at higher concentration of the cytokinins, and after three subcultures of the callus on solid MS medium amended with the same concentration of the cytokinins, in vitro organogenesis was not observed. Further cultivation of the morphogenic callus cultures in liquid medium was insufficient in stimulating shoot/bud primordium formation or somatic embryogenesis (SE). The callus cultures were cultivated on the same PGRs-amended medium for at least three passages and in vitro morphogenesis in the form of shoot bud/primordial or somatic embryogenesis (SE) not stimulated. However, variable growth and degree of callus morphologies were observed in most of the cultures (Figure 11-w). Due to its high cytokinin activity, TDZ is regarded most effective PGR for promoting in vitro morphogenesis in woody plants, and even at low concentration can facilitate efficient in vitro response of recalcitrant plants by initiating shoot bud primordial formation, SE or callus induction (Huetteman and Preece, 1993). The intricate morphogenesis signal routes induced by PGRs are yet unclear but, treatment with their concentrations had stimulated formation of nodular-green morphogenic callus in many plants (Zambre et al., 2001; Kehie et al., 
2012). In the present experiment, cultivation of $C$. fragrans callus cultures on solid medium added with $0.5 \mathrm{mg}$ $\mathrm{L}^{-1}$ of the cytokinins could not induce differential callus morphology about PGRs-free media cultivation. However, with the TDZ slight change in morphology of the callus cultures into dark brown was observed. The dark browning showed increased intensity accompanied by increased compactness of callus cultures with an increase in concentration of TDZ amended in the cultivation medium (Figure 1t-w). In many reported studies in the literature lower levels of the TDZ was found sufficient for stimulating shoot organogenesis from cotyledonary explant while higher concentrations promoted SE (Guo et al., 2011). Cultivation of rhizogenic callus cultures on medium supplemented with lower levels of the TDZ stimulated shoot formation and SE at low frequency (Chhabra et al., 2008) while it promoted formation of embryogenic callus from root tip, stem and leaf segments explants (Hsia and Korban, 1996). Thidiazuron at low or high concentration was found efficient in stimulating high frequency shoot morphogenesis from shoot tip-derived callus cultures (Wamaitha et al., 2010). It was also found efficient for the induction of shoot from seed embryo-derived callus cultures (Ning and Bao, 2007; Gurel et al., 2009). However, in an instance, cultivation on TDZ-supplemented medium induced semi-compact callus without organogenesis (Canli, 2003). The green pigmentation showed increased intensity at higher concentration of the cytokinins, and after three subcultures of the callus on solid medium supplemented with the same concentration of the cytokinins, in vitro morphogenesis was not observed. Due to unhindered diffusion of media components permitted in liquid medium cultivation, morphogenic response of in vitro cultures can be initiated by an enhanced uptake of nutrients and supplements, as found efficient in stimulating in vitro morphogenesis with many species (Tomaszewska-Sowa, 2012; Sanputawong et al., 2015). In the present study, when green non-organogenic callus cultures were cultivated in liquid medium (Figure 1 $\mathrm{y}-\mathrm{z}, 1)$ with a weekly replenishment of medium nutrients, in vitro morphogenesis was not stimulated after four weeks and subsequent sub-cultivations of the callus cultures, suggesting that $C$. fragrans is recalcitrant to indirect organogenesis at least from seed embryo-derived callus cultures under the experimental conditions of the present study. The fact was supported by additional experiment to assess the synergistic action of cytokinins with auxin and its capacity to stimulate formation of organized structures. Callus cultures were cultivated on solid medium amended with low levels of NAA in addition to cytokinins concentrations tested. Such cultivation could not result in substantial difference in morphogenic response observed with the other cytokinins concentrations. Even at low levels, the addition of BAP or Kinetin (Kin) has been found efficient for shoot initiation with many medicinal and woody plants (Li and Liu, 2003; Nishitha et al., 2006; Saini et al., 2012; Isah and Mujib, 2013; Sanputawong et al., 2015) and with some of the plants, it promoted cell growth along with morphogenic callus formation without organogenesis. For instance, it occurred at higher rate in liquid over solid medium cultivation with synergistic response obtained when auxin was supplemented along with the cytokinins (Mulder-Krieger et al., 1982; Li and Liu, 2003; Bienaime et al., 2015). In this study, transfer of the morphogenic callus cultures into liquid medium were ineffective in stimulating formation of organized structures from the callus cultures. Browning effect due to the latex and phenolics release from callus cultures into cultivation medium that resulted in callus necrosis was observed but, amending ascorbic acid $\left(1.0 \mathrm{mg} \mathrm{L}^{-1}\right)$ into the cultivation medium overcame the effect without organogenesis capacity shown by the cultures (Figure $1 \mathrm{x}, 1-2)$. In other reported studies in the literature, indirect shoot morphogenesis from callus induced from various explants involved formation of hard, green and compact calli on cytokinins-amended medium, and occurred at very low frequency to absent even after second sub-cultivation of callus due to hardening and habituation (Malik et al., 2007; Saini et al., 2012). In Garcinia mangostana, BAP stimulated formation of nodular callus before shoot organogenesis from leaf-derived callus cultures (Qosim et al., 2013) while shoot morphogenesis and SE were stimulated by its different concentrations when cotyledonary leaf segment-derived callus cultures of Digitalis lamarckii were cultivated on medium added with the PGR (Verma et al., 2011). Cultivars-based differential organogenesis was observed when mature seed embryo-derived callus cultures were cultivated on medium amended with different concentrations of BAP (Roy et al., 2012; Sankepally and Singh, 2016) while genotypes-dependent differential regeneration efficiency occurred with callus cultivated on medium amended with combinations of BAP and Kin (Vila, 2004). In the callus cultures of Actinidia chinensis 
var. deliciosa A. Chev. (A. Chev.), also known as Kiwifruit, formation of "ball-shaped" region of the calli covered with closely attached cells and membranous layer was the first indicator of shoot bud initiation while adjacent non-morphogenic calli were composed of loosely arranged cells with irregular appearance on the surface (Czernicka et al., 2021). Although Kin has been used to stimulate indirect organogenesis with many species, it is less efficient than BAP in most of the reported literature due to higher efficiency of plant tissues to metabolize BAP over Kin and enhanced stimulating effect it has on biosynthesis of endogenous hormones in plant tissues (Qosim et al., 2013; Miao et al., 2016). Superior degree of callus pigmentation stimulated by BAP over Kin concentrations observed in the present experiment supports the explanation. However, low and higher concentrations of the two cytokinins was found insufficient in stimulating formation of organized structures from the callus cultures, possibly due to genetic background of $C$. fragrans that lack capacity for indirect regeneration from seed (mature) embryo-derived callus cultures as competence for indirect organogenesis is species and explant-specific in some plants. Ability of in vitro cultivated plant cells, tissues or organ to respond to exogenous applied PGRs in a cultivation medium with resultant morphogenic response is dependent on the balanced interaction between endogenous and exogenous factors of culture conditions (Skoog and Miller, 1957; Vila, 2004; Isah, 2015b). Therefore, inherent capacity to synthesize and respond to exogenous applied cytokinins is essential for successful induction of in vitro morphogenesis in plants; higher capacity to synthesize cytokinins imply more responsiveness to shoot organogenesis. Increasing concentration of the PGRs in the cultivation medium is irrelevant when cultivated tissue is unresponsive to the in vitro morphogenesis (Miao et al., 2016).

Somatic embryogenesis is an in vitro morphogenic program by which somatic plant cells acquire competence for the formation of embryogenic tissue which further differentiates into somatic embryos through its various developmental stages (Zimmerman, 1993; Feher, 2019). Strategies that involve manipulating culture medium composition and conditions can be employed to switch somatic program to the embryogenic in a plant in vitro culture system (Carman, 1990; Ikeuchi et al., 2013; Isah, 2016). In the present study, callus cultures were cultivated on solid medium amended with 2,4-D $\left(3.0 \mathrm{mg} \mathrm{L}^{-1}\right)$ for at least three passages before used in the SE study. Cultivation of the callus cultures on PGRs-free medium (control), lower concentrations of 2,4-D or NAA $\left(0.25,0.5,1.0 \mathrm{mg} \mathrm{L}^{-1}\right)$ and their combinations with BAP, TDZ or Kin $\left(0.25,0.5,1.0 \mathrm{mg} \mathrm{L}^{-1}\right)$ were found insufficient for stimulating embryogenic tissue formation and $S E$ expression, suggesting that at least for mature seed embryo-derived callus cultures and under the experimental condition of the study, SE is not attainable in C. fragrans. Although indirect in vitro plant regeneration is the most appropriate developmental pathway for genetic improvement of high-value medicinal plants, the explant and genotype, PGRs type and concentration amended in the cultivation medium, and conditions of physical environment determine the morphogenic response. With some of the plants, the response is not attainable, as observed in an experiment with mature seed embryo-derived callus cultures of $C$. fragrans in the present study. 


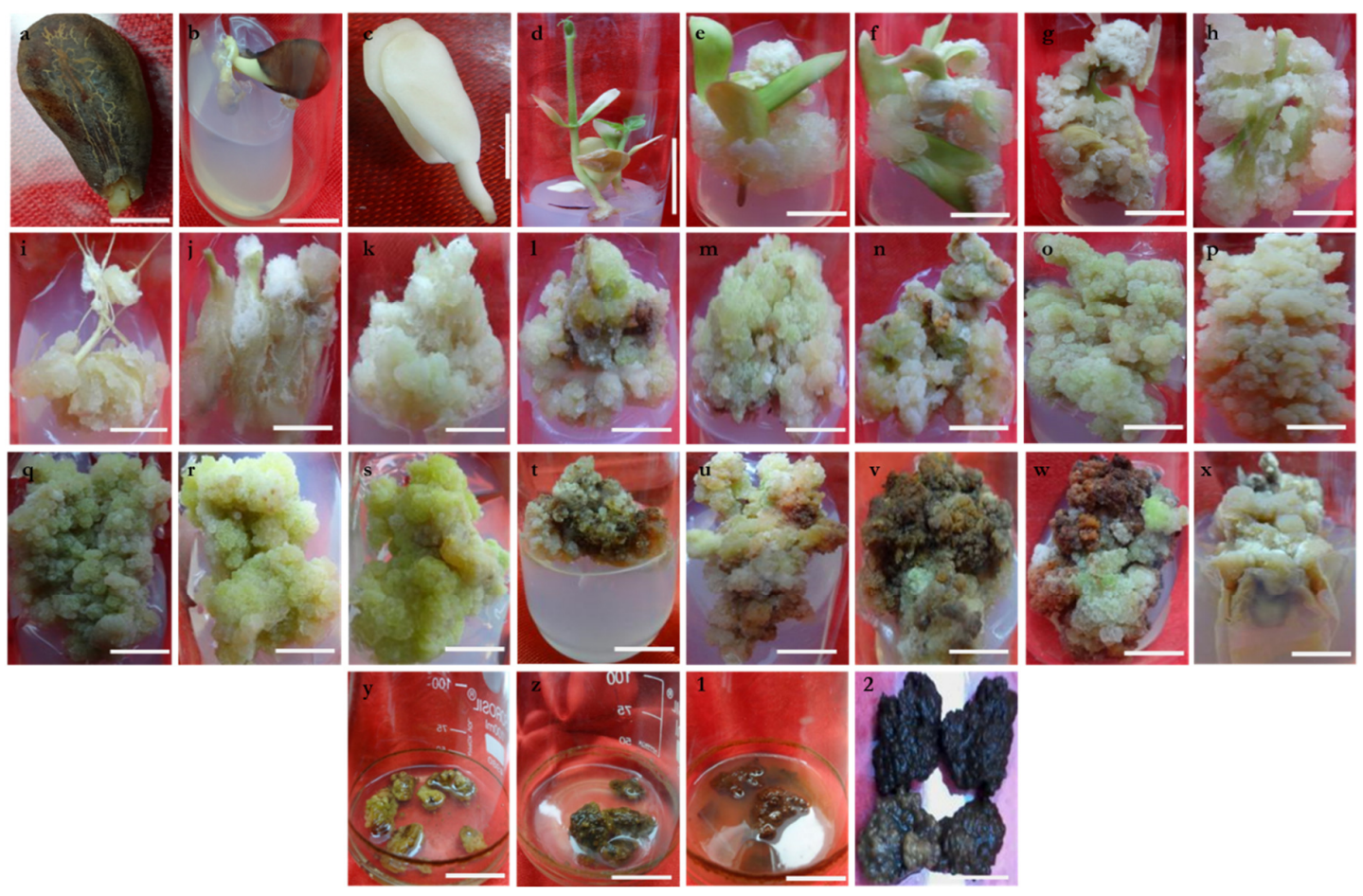

Figure 1. a) Surface sterilized mature seed with a slanted cut at the radicular end; b) In vitro germination of the seed on half strength basal MS medium amended with $\mathrm{GA}_{3}\left(1.0 \mathrm{mg} \mathrm{L}^{-1}\right)$; c) Seed embryo axes excised from surface sterilized seeds; d) Aseptic seedling obtained from seed embryo axes after four weeks culture; e) Induction of callus on MS medium added with 2,4-D +BAP $\left(3.0+1.0 \mathrm{mg} \mathrm{L}^{-1}\right)$ using seed embryo axes; f) Cotyledons; g) Leaf; h) Hypocotyl; i-j) Root explants; k) Seed embryo-derived callus biomass production on MS medium amended with same PGRs as the induction medium; l) Morphology of the callus cultures cultivated on MS medium amended with $\left.\left.\operatorname{Kin}\left(1.0 \mathrm{mg} \mathrm{L}^{-1}\right) ; \mathbf{m}\right) \operatorname{Kin}\left(2.0 \mathrm{mg} \mathrm{L}^{-1}\right) ; \mathbf{n}\right) \operatorname{Kin}(3.0$ $\left.\mathrm{mg} \mathrm{L}^{-1}\right)$; o) Kin $\left(4.0 \mathrm{mg} \mathrm{L}^{-1}\right)$; p) BAP $\left(1.0 \mathrm{mg} \mathrm{L}^{-1}\right)$; q) BAP $\left.\left(2.0 \mathrm{mg} \mathrm{L}^{-1}\right) ; \mathbf{r}\right)$ BAP $\left(3.0 \mathrm{mg} \mathrm{L}^{-1}\right)$; s) BAP $(4.0$ $\left.\mathrm{mg} \mathrm{L}^{-1}\right) ; \mathbf{t}$ ) Thidiazuron $\left.\left.\left(1.0 \mathrm{mg} \mathrm{L}^{-1}\right) ; \mathbf{u}\right) \mathrm{TDZ}\left(2.0 \mathrm{mg} \mathrm{L}^{-1}\right) ; \mathbf{v}\right) \mathrm{TDZ}\left(3.0 \mathrm{mg} \mathrm{L}^{-1}\right)$ and $\left.\mathbf{w}\right) \mathrm{TDZ}\left(4.0 \mathrm{mg} \mathrm{L}^{-1}\right)$; $\mathbf{x})$ Formation and leaching of latex into the culture medium leading to the callus browning; $y$ ) Morphogenic callus (green) cultivation in liquid medium amended with BAP $\left(3.0 \mathrm{mg} \mathrm{L}^{-1}\right)$; z) Callus browning after two weeks cultivation in liquid medium; 1) three weeks cultivation; 2) five weeks cultivation (Fig. $1 \mathrm{a}-\mathrm{b}, \mathrm{d}-\mathbf{x}, 2$ scale bars $1.5 \mathrm{~cm}, \mathrm{c}$ scale bars $0.8 \mathrm{~cm}, \mathbf{y}-1$ scale bars $1.9 \mathrm{~cm}$ ).

\section{Production of camptothecin}

Because cultivation of the callus in liquid medium could not stimulate organogenesis, biomass production and CPT content of the callus cultures and in the liquid medium cultivation system (of triplicate experiments) were analyzed. Production of CPT from the callus cultures as well as in the cultivation medium were evaluated to assess their influence on biosynthetic capacity of alkaloid in comparison with solid medium cultivation. Variation in biomass production and CPT yield observed with the solid medium cultivation were similarly obtained in the liquid. However, yield of CPT in callus cultures was reduced to about half the productivity obtained on solid medium cultivation system but overall productivity relatively higher (Figure 2BF), despite the possibility that leached CPT in liquid medium cultures had gotten degraded with resultant effect in alkaloid yield (Isah, 2017; Isah and Umar, 2019).

In all the cytokinins concentrations tested, BAP had more enhancing effect on biomass and CPT biosynthesis over Kin and TDZ up to certain levels. However, the production was dependent on culture medium type, i.e., solid or liquid. Corresponding higher production of biomass was achieved in liquid medium cultivation of the callus over the solid added with BAP $\left(4.0 \mathrm{mg} \mathrm{L}^{-1}\right)$ and its combination with NAA $(0.5 \mathrm{mg} \mathrm{L}$ 
$\left.{ }^{1}\right)$. For the solid medium cultivation of the callus cultures, maximum of $1.72 \mathrm{~g}$ and $2.11 \mathrm{~g}$ absolute callus biomass was produced on BAP-amended medium after 21 days culture over the lowest with TDZ where $1.31 \mathrm{~g}$ and 1.51 $\mathrm{g}$ were produced. Liquid medium cultivation enhanced production of the biomass with $2.39 \mathrm{~g}$ and $2.49 \mathrm{~g}$ absolute biomass generated by BAP-amended cultures. Correspondingly, TDZ produced $1.81 \mathrm{~g}$ and $1.95 \mathrm{~g}$ absolute biomass at similar amended concentration to that of BAP and culture duration (Figure 2B-C). In this study, yield of CPT from callus biomass showed similar productivity trend between solid medium cultivation to that of liquid medium and biomass accumulation. However, productivity of callus grown in liquid medium (intracellular CPT) was relatively lower than that of solid medium cultivation, which can be explained by the leaching effect of the alkaloid (extracellular) in the case of liquid medium cultivation; overall CPT produced by liquid medium cultures was higher (Figure 2D-F).

\section{Production of camptothecin in explants and resultant callus cultures}

Capacity to produce a bioactive molecule produced by ex vitro grown plant when cultivated in the in vitro condition at differential yield was recognized decades ago but, exploiting endangered plant sources of CPT is relied upon for its supply to pharmaceutical industry for anticancer drugs production (Isah et al., 2018). Production of the alkaloid from plant sources is yet to reach commercial application using PCTOC techniques, which has resulted in an endangered status to most plant sources and increasing interest to apply biotechnological strategies of PCTOC in producing CPT (Isah and Mujib, 2015b, c; Isah et al., 2018). Biosynthesis of the plant secondary metabolites that include CPT shows close correlated expression with morphological and cytological differentiation. However, the degree of the production and its dependence on development is unknown, whether it is genetic or physiological phenomenon in plant cells and tissues (Kai et al., 2015). In the present study, evaluation of CPT content in the various explants of 4-weeks-old aseptic seedling, mature seed embryo axes and resultant callus cultures revealed that maximum production of the alkaloid was in roots explant $(0.019 \%)$. This was followed by mature seed embryos $(0.0053 \%)$, cotyledons $(0.0039 \%)$, hypocotyls $(0.0024 \%)$ and leaves $(0.0017 \%)$. Yield of the alkaloid showed significant difference between most of the explants except in seed embryos and cotyledons (Figure 2A). However, production of the alkaloid was reduced in callus induced from the explants, and no variation in CPT content of callus cultures derived from various explants was observed. In the reported literature, many studies have shown variations in biosynthetic capacity for alkaloids in differentiated and undifferentiated in vitro-raised cells and tissues (Ikuta et al., 1974; Murthy et al., 2014; Isah and Mujib, 2015b, c;) and includes anticancer alkaloids such as CPT (Facchini and Bird, 1998; Yamazaki et al., 2010; Sankar-Thomas et al., 2011; Kai et al., 2015). For instance, biosynthesis of cardenolides and benzylisoquinoline alkaloids in the callus cultures was reported to be dependent on organ redifferentiation (Ikuta et al., 1974; Hagimori et al., 1980; Facchini and Bird, 1998), as in morphine alkaloid production as well (Yoshikawa et al., 1985). Green callus cultures that differentiated epidermis and vascular bundles produced alkaloids while cells with limited degree of differentiation contained codeine as the principal alkaloid but the level of morphine production increased as tissue differentiates (Yoshikawa et al., 1985), similar to observation made in the present study.

\section{Influence of PGRs on production of camptothecin in seed embryo-derived callus biomass}

Plant growth regulators are instrumental composition of culture medium that have profound effect on cell growth, cyto-differentiation and alkaloid production in the in vitro plant cell cultures (Jaleel et al., 2009) and their type, concentration and modification is an effective tool for optimizing cultures condition and improved in vitro biosynthesis of alkaloid (Murthy et al., 2014; Bienaime et al., 2015). In the present study, production of CPT from callus cultures (after dried to constant mass) and in the culture medium were evaluated to assess its influence on biosynthetic capacity about solid medium cultivation. Variation in biomass production and CPT content yield observed with the solid medium cultivation system was similarly obtained in the liquid. However, yield of CPT in the callus cultures were reduced to about half the productivity obtained on solid medium cultivation system but, overall productivity relatively higher (Figure 2B-F), despite the 
possibility of degradation of the leached CPT in liquid medium cultivation system (Karwasara and Dixit, 2013; Isah, 2017). In order to evaluate the influence of PGRs on biomass production and CPT biosynthesis capacity in the $C$. fragrans callus cultures, absolute biomass production in callus obtained from in vitro morphogenesis study and CPT production were evaluated by the assessment of fresh and dried weight, alkaloid extracted and HPTLC analysis performed (Isah, 2019; Isah and Umar, 2019). The PGRs amended in the cultivation medium had influential effect on biomass and CPT biosynthetic capacity of the callus cultures over control, and the substantial effect was based on type and concentration of PGRs amended in the cultivation medium (Figure 2D-E). Control callus cultures cultivated on PGRs-free medium showed lowest biomass and CPT production when compared with the cytokinins-amended medium cultures, suggesting substantial effect of PGRs on the production of biomass and CPT biosynthesis in C. fragrans (Figure 2B-F). In all the tested concentrations, BAP had more enhancing effect on biomass and CPT biosynthesis over Kin and TDZ. However, the production was dependent on the culture medium type, i.e., solid or liquid medium cultivation system. Corresponding higher production of biomass was achieved in liquid medium cultivation of the callus over the solid added with BAP $\left(4.0 \mathrm{mg} \mathrm{L}^{-1}\right)$ and its combination with NAA $\left(0.5 \mathrm{mg} \mathrm{L}^{-1}\right)$. In the case of solid medium cultivation of the callus cultures, maximum of $1.72 \mathrm{~g}$ and $2.11 \mathrm{~g}$ absolute callus biomass was produced on BAPamended medium after 21 days culture over the lowest with the TDZ where $1.31 \mathrm{~g}$ and $1.51 \mathrm{~g}$ were produced (respectively) on medium added with their concentrations. Liquid medium cultivation enhanced production of the biomass with maximum of $2.39 \mathrm{~g}$ and $2.49 \mathrm{~g}$ absolute biomass generated by BAP-amended cultures. Correspondingly, TDZ produced $1.81 \mathrm{~g}$ and $1.95 \mathrm{~g}$ absolute biomass at similar amended concentration to the $\mathrm{BAP}$ and combinations, and culture duration (Figure 2B-C). Yield of the alkaloid showed similar productivity trend to that of the callus cultures cultivated on solid and in the liquid medium systems. However, the productivity of callus cultures grown in liquid medium (intracellular CPT) was relatively lower than that of solid medium cultivation, which can be explained by the leaching effect of the alkaloid (extracellular) in the case of liquid medium cultivation systems. However, the overall CPT produced by liquid medium cultures were relatively higher (Figure 2D-F); maximum production of CPT was achieved with BAP and its combination with the NAA where combined intracellular $(0.00063+0.00072 \mathrm{mg} / \mathrm{g}$ calli $\mathrm{DW})$ and extracellular $(0.00071+0.00079 \mathrm{mg} / 2 \mathrm{~mL}$ medium) were biosynthesized, which is relatively higher to that of the solid medium cultivation. Solid medium cultures produced maximum of $0.00093 \mathrm{mg} / \mathrm{g}$ calli DW and $0.00098 \mathrm{mg} / \mathrm{g}$ calli DW respectively. Correspondingly, TDZ and its combination with NAA produced lowest with combined intracellular $(0.00035 \mathrm{mg} / \mathrm{g}$ calli DW, $0.00047 \mathrm{mg} / \mathrm{g}$ calli DW) and extracellular CPT $(0.00044 \mathrm{mg} / 2 \mathrm{~mL}$ medium, $0.00053 \mathrm{mg} / 2 \mathrm{~mL}$ medium) yield, been higher than that produced by solid medium cultivation of the callus cultures $(0.00064 \mathrm{mg} / \mathrm{g}$ calli DW and $0.00077 \mathrm{mg} / \mathrm{g}$ calli DW), respectively (Fig. 2D-F). Cytokinins have enhancing effect on secondary metabolites production and enhance the biosynthesis in the plant in vitro cell cultures by their type and concentration amended in the cultivation medium (Bienaime et al., 2015; Raj et al., 2015). Purine-type of the cytokinins have beneficial effect on alkaloids production in the in vitro cultures without adverse effect on callus growth while phenylurea derivatives either inhibit growth of cultures or highly improve biomass production at the expense of alkaloids biosynthesis (Bienaime et al., 2015). Therefore, modification of their combination and ratio is an effective strategy for studying plant secondary metabolites biosynthetic capacity of cultures during in vitro morphogenesis (Karwasara and Dixit, 2013; Bienaime et al., 2015). For instance, in the tender-stem induced callus cultures of Securinega suffruticosa, production of biomass and virosecurinine alkaloids was influenced by sucrose concentration and PGRs amended in the cultivation medium, and combination of Kin with NAA was the best for the productivity (Yuan et al., 2007). Biosynthesis of indolizidine alkaloids in the cultivated callus cultures of the same species was also enhanced when cytokinins were amended in the cultivation medium and when in combination with auxins (Raj et al., 2015). Kinetin enhanced production of the alkaloids but, no correlation between concentration amended in the culture medium and alkaloids production was established. In the study, about 2-fold enhanced biosynthesis of securinine was stimulated in the callus cultures by TDZ treatment. However, allosecurinine level was negatively affected while PGR-free medium cultivation resulted in low production of the indolizidine alkaloids, 
suggesting the substantial effect of PGRs on biosynthesis of alkaloids (Verpoorte et al., 1991; Raj et al., 2015). In previous study with $N$. nimmoniana callus cultures, biomass and CPT production were influenced by the culture medium type and cultivation duration (Isah, 2017). In the study, significant proportion of the synthesized CPT was leached into the culture medium, resulting into lower yield in its callus cultures. However, cultivating callus cultures on cytokinins supplemented-medium such as Kin or BA influenced biosynthetic capacity of alkaloids, and higher concentrations inhibited the yield (Mulder-Krieger et al., 1982). Biosynthesis of indolizidine alkaloids in the callus cultures of $S$. suffruticosa was enhanced by the type and concentration of cytokinins amended in the cultivation medium, as well as its synergistic action with auxins (Raj et al., 2015). In Phyllanthus glaucus shoot cultures, cytokinins types, their combination with auxins or auxins-alone and concentrations supplemented in the cultivation medium influenced the levels of securinega-type alkaloids and biomass production in differential manner (Sparzak-Stefanowska et al., 2019). Only BAP enhanced production of the alkaloids while other cytokinins showed inhibitory effect to the securinega-type alkaloids biosynthesis. In the present study, the observed low production of CPT in C. fragrans callus cultures cultivated in liquid medium could be explained by the leaching effect of the alkaloid into cultivation medium and its possible degradation. In callus cultures of Cinchona pubescence, PGRs and culture conditions affected biosynthesis of alkaloids (Mulder-Krieger et al., 1982) while culture medium of cultivation and PGRs influenced CPT yield in Camptotheca acuminata (van Hengel et al., 1992). Application of BA enhanced yield of the alkaloid and morphogenic parameters in C. acuminata callus cultures (Saini et al., 2012). Rhizome explant-derived morphogenic callus cultures of Alpinia galanga obtained on BAP-added medium produced significant phytoconstituents at higher levels over the non-morphogenic (Rao et al., 2011). 


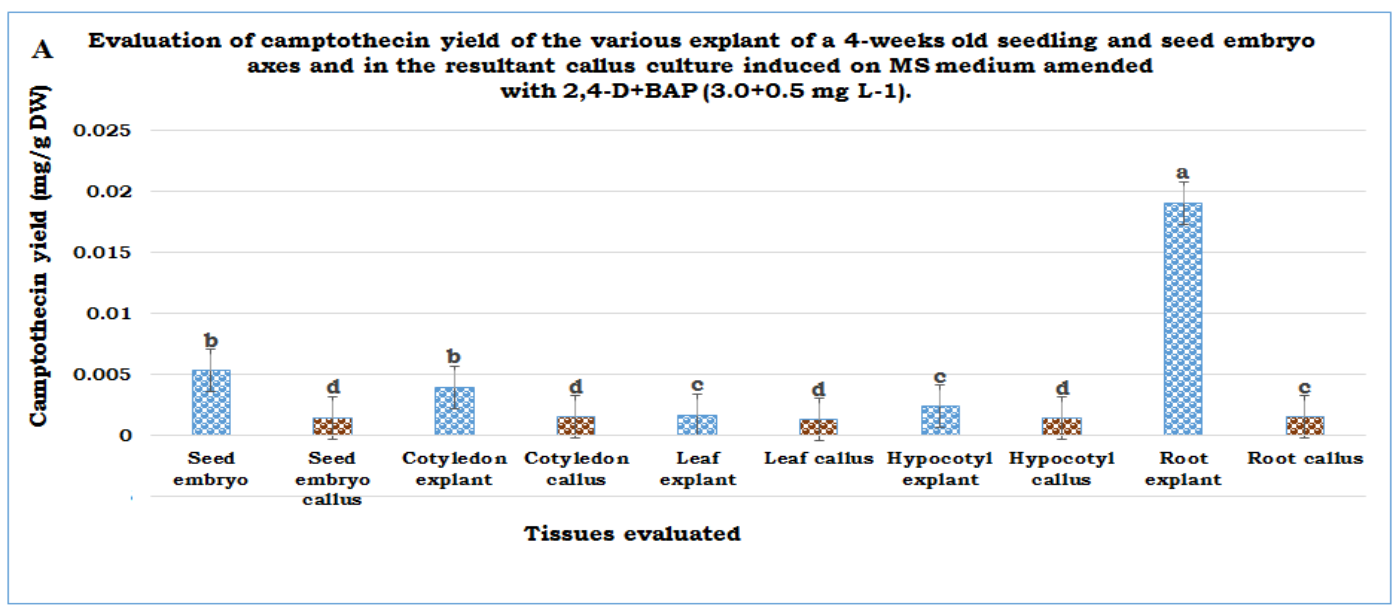

B Effect of plant growth regulator types and concentrations on absolute biomass production in the callus cultures of Chonemorpha fragrans cultivated on solid MS medium

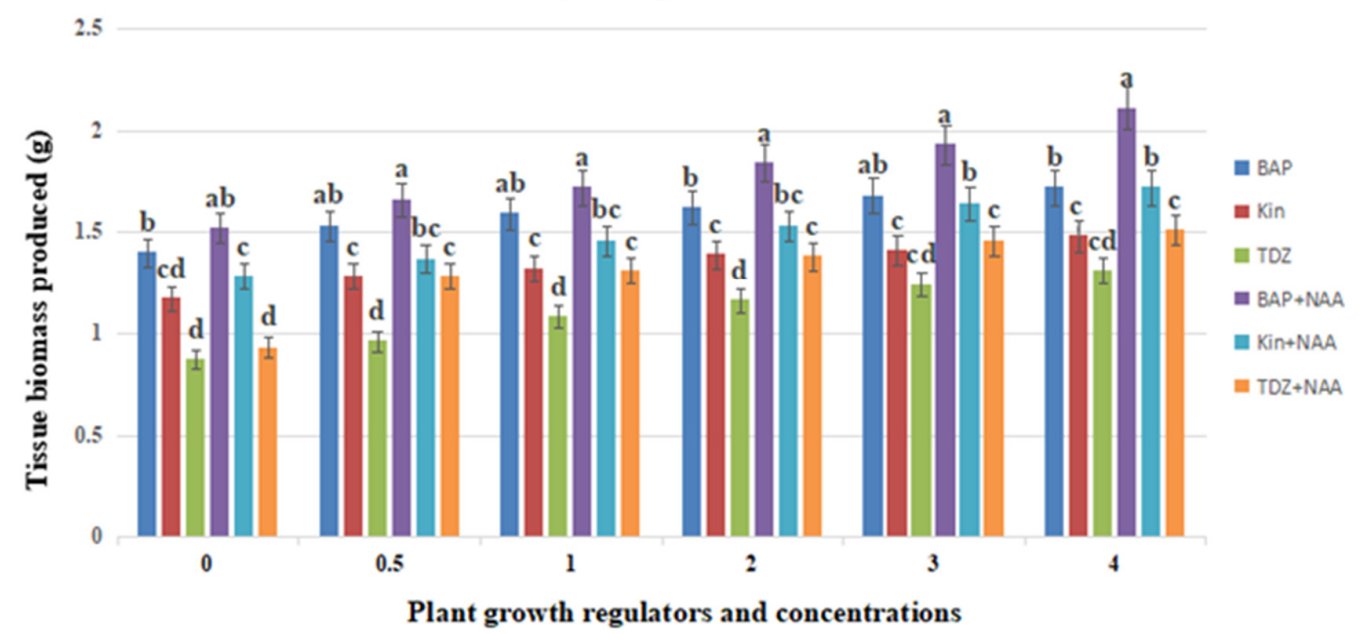
C Effect of plant growth regulator types and concentrations on absolute biomass production in the callus cultures of Chonemorpha fragrans cultivated in liquid MS medium

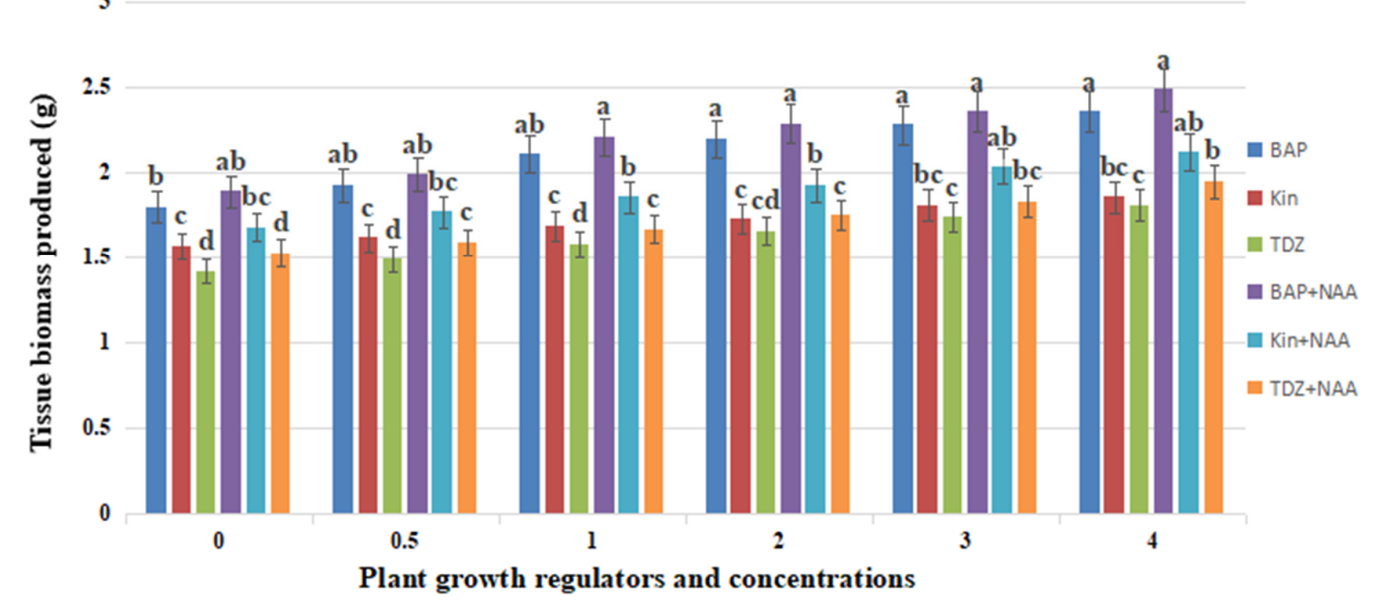


D Effect of plant growth regulator types and concentrations on production of camptothecin in the callus cultures of Chonemorpha fragrans cultivated on solid MS medium

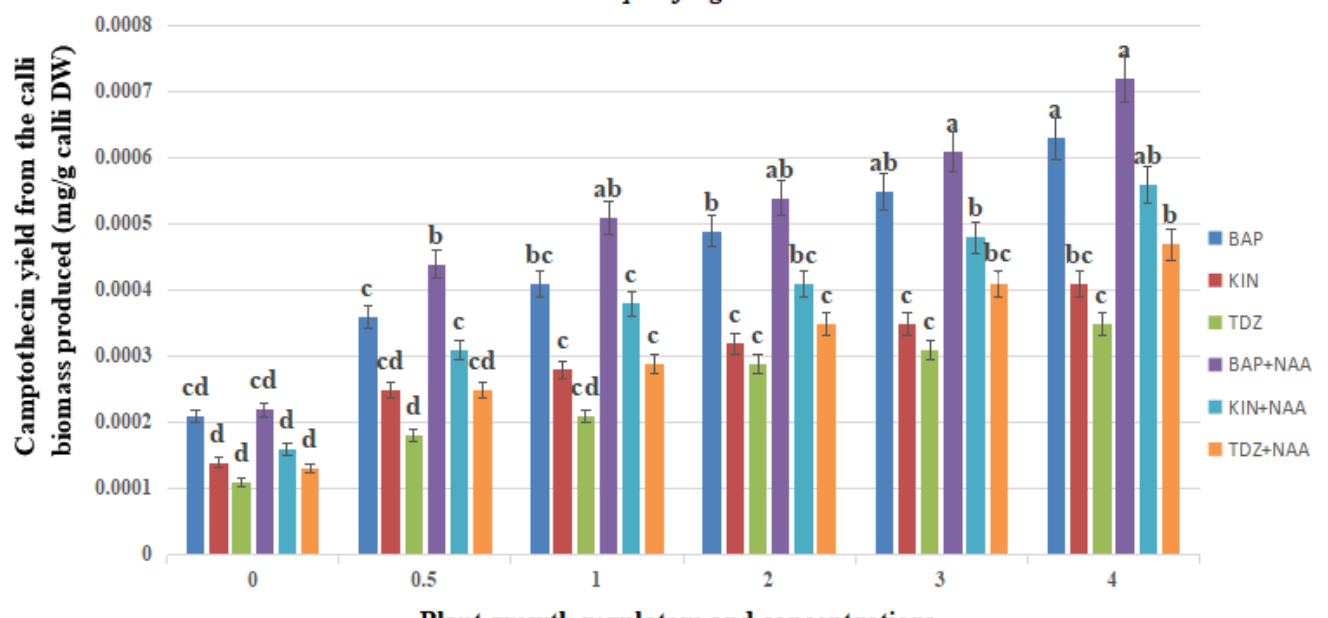

Plant growth regulators and concentrations

$\mathbf{E}$

Effect of plant growth regulator types and concentrations on the production of intracellular camptothecin in the callus cultures of Chonemorpha fragrans cultivated in liquid MS medium

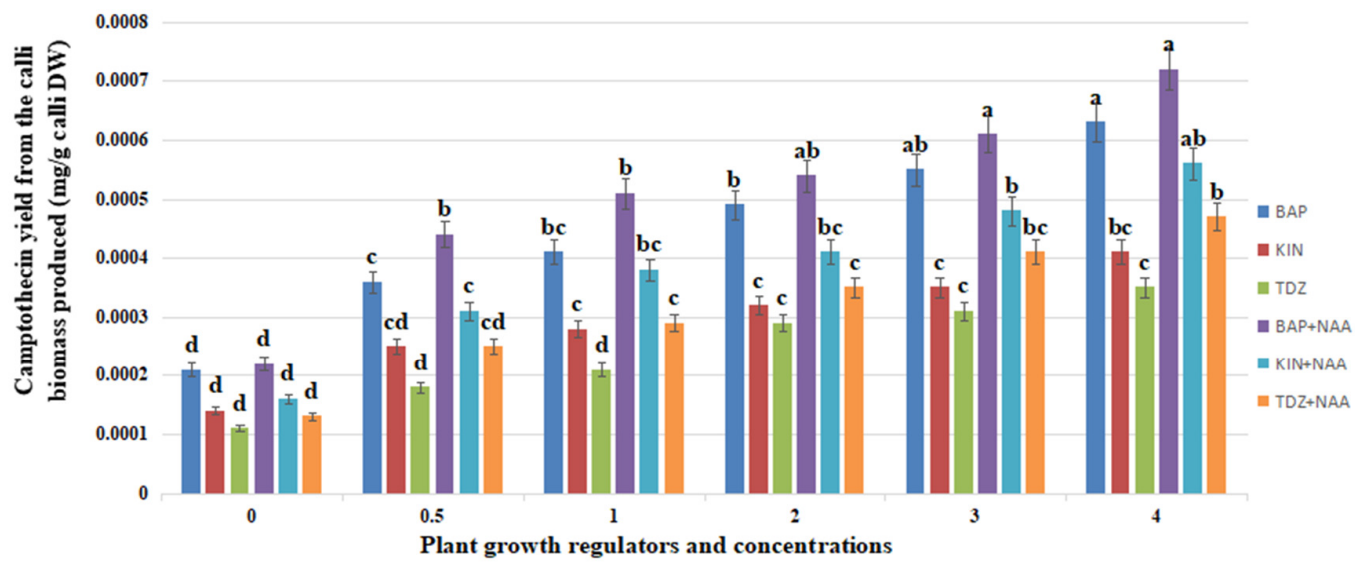

F Effect of plant growth regulator types and concentrations on the production of extracellular camptothecin in the callus cultures of Chonemorpha fragrans cultivated in liquid MS medium

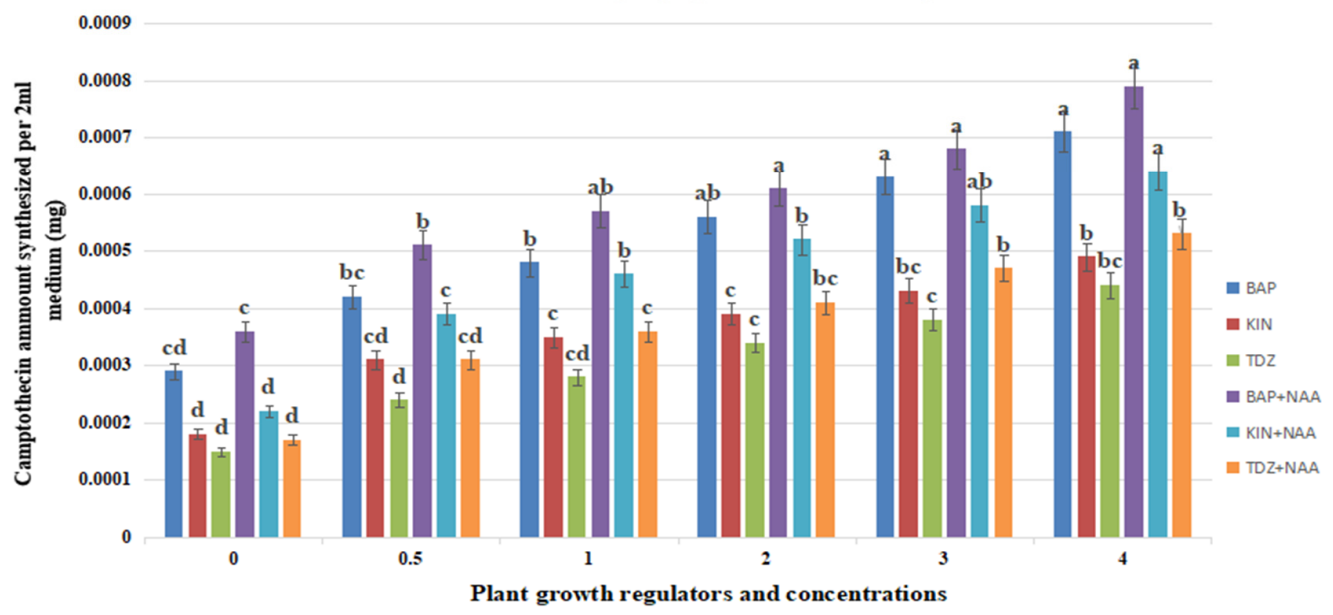

Figure 2. A-F evaluation of biomass and camptothecin production in the explants and resultant callus cultures of C. fragrans 


\section{Conclusions}

In conclusion, results of the present study suggests that cytokinins and their combination with auxin exerts substantial influence on biomass and CPT production along with morphogenic callus formation without organogenesis/SE response from mature seed embryo-derived callus cultures of $C$. fragrans when cultivated on solid or in liquid medium supplemented with the PGRs. Supply of the CPT raw material to pharmaceutical industry for production of its analog drugs approved for chemotherapy of cancer is relied upon exploitation of plants, leading to endangered status to the natural plant sources. Production of the alkaloid from the plant sources is affected by many barriers such as collection season and extraction difficulties among others. However, the barriers can be overcome by developing biotechnological production systems, due to the ease at which alkaloids can be obtained from in vitrocultures when compared to field grown plants. Complex tissue structure of plants makes indirect organogenesis an alternative strategy for developing transgenic plants, with application in the production of CPT. However, the morphogenic pathway could not be achieved with $C$. fragrans using mature seed embryo-derived callus cultures, at least under the experimental conditions tested in the present study. Thus, callus cultures offer alternative tissue-source for the large-scale production and isolation of CPT to overcome the seasonal and other barriers in sourcing from plants, so as to conserve natural population and meet demand of pharmaceutical industry for CPT raw material supply used in production of its analog drugs.

\section{Authors' Contributions}

Both authors read and approved the final manuscript.

\section{Acknowledgements}

Authors thank Department of Biotechnology, Government of India New Delhi for financial support towards carrying out the research work and its publication.

\section{Conflict of Interests}

The authors declare that there are no conflicts of interest related to this article.

\section{References}

Banerji J, Chatterji A (1973). A new steroidal alkaloid from Chonemorpha fragrans (Moon) Alston. Iranian Journal of Chemistry 56:1056-57.

Bienaime C, Melin A, Bensaddek L, Attoumbre J, Nava-Saucedo E, Baltora-Rosset S (2015). Effects of plant growth

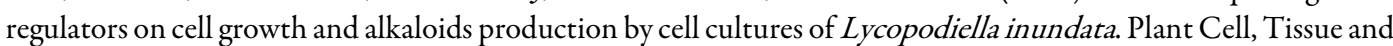
Organ Culture 123(3):523-533. https://doi.org/10.1007/s11240-015-0856-6

Canli FA (2003). Effects of dark and TDZ on callus formation of rose leaf explants. Pakistan Journal of Biological Sciences 6(19):1672-1674. https://doi.org/10.3923/pjbs.2003.1672.1674

Carman JG (1990). Embryogenic cells in plant tissue cultures: occurrence and behavior. In Vitro Cellular and Developmental Biology - Plant 26(8):746-753. https://doi.org/10.1007/BF02623615

Chhabra G, Chaudhary D, Varma M, Sainger M, Jaiswal PK (2008). TDZ-induced direct shoot organogenesis and somatic embryogenesis on cotyledonary node explants of lentil (Lens culinaris Medik.). Physiology and Molecular Biology of Plants 14(4):347-353. https://doi.org/10.1007/s12298-008-0033-Z 
Clarance P, Khusro A, Lalitha J, Sales J, Paul A (2019). Optimization of camptothecin production and biomass yield from endophytic fungus Fusarium solani strain ATLOY-8. Journal of Applied Pharmaceutical Science 9(10):035-046. https://doi.org/10.7324/JAPS.2019.91005

Czernicka M, Chlosta I, Keska K, Kozieradzka-Kiszkurno M, Abdullah M, Popielarska-Konieczna M (2021). Protuberances are organized distinct regions of long-term callus: histological and transcriptomic analysis in kiwifruit. Plant Cell Reports 40:637-665. https://doi.org/10.1007/s00299-021-02661-0

Espinosa-Leal CA, Puente-Garza CA, García-Lara S (2018). In vitro plant tissue culture: means for production of biological active compounds. Planta 248:1-18. https://doi.org/10.1007/s00425-018-2910-1

Facchini PJ, Bird DA (1998). Developmental regulation of benzylisoquinoline alkaloid biosynthesis in opium poppy plants and tissue cultures. In Vitro Cellular and Developmental Biology - Plant 34(1):69-79. https://doi.org/10.1007/BF02823126

Fehér A (2019). Callus, dedifferentiation, totipotency, somatic embryogenesis: what these terms mean in the era of molecular plant biology?. Frontiers in Plant Science 10:536. https://doi.org/10.3389/fpls.2019.00536

Fulzele DP, Satdive RK (2003). Somatic embryogenesis, plant regeneration, and evaluation of camptothecin content in Nothapodytes foetida. In Vitro Cellular and Developmental Biology - Plant 39(2):212-216. https://doi.org/10.1079/IVP2002368

Guo B, Abbasi BH, Zeb A, Xu LL, Wei YH (2011). Thidiazuron: a multidimensional plant growth regulator. African Journal of Biotechnology 10(45):8984-9000. https://doi.org/10.5897/AJB11.636

Gurel F, Karakas O, Albayrak G, Ari S (2009). Regeneration capacity of mature embryo-derived callus in barley (Hordeum vulgare L.). Acta Biologica Hungarica 60(3):309-319. https://doi.org/10.1556/ABiol.60.2009.3.8

Hagimori M, Matsumoto T, Kisaki T (1980). Studies on the production of Digitalis cardenolides by plant tissue culture I. Determination of digitoxin and digoxin contents in first and second passage calli and organ redifferentiating calli of several Digitalis species by radioimmunoassay. Plant and Cell Physiology 21(8):1391-1404. https://doi.org/10.1093/pcp/21.8.1391

Hsia CN, Korban SS (1996). Organogenesis and somatic embryogenesis in callus cultures of Rosa hybrida and Rosa chinensis minima. Plant Cell, Tissue and Organ Culture 44(1):1-6. https://doi.org/10.1007/BF00045906

Huetteman CA, Preece JE (1993). Thidiazuron: a potent cytokinin for woody plant tissue culture. Plant Cell, Tissue and Organ Culture 33(2):105-119. https://doi.org/10.1007/BF01983223

Ikeuchi M, Sugimoto K, Iwase A (2013). Plant callus: mechanisms of induction and repression. The Plant Cell 25(9):3159-3173. https://doi.org/10.1105/tpc.113.116053

Ikuta A, Syono K, Furuya T (1974). Alkaloids of callus tissues and redifferentiated plantlets in the Papaveraceae. Phytochemistry 13(10):2175-2179. https;//doi.org/10.1016/0031-9422(74)85023-5

Isah T (2015a). Adjustments to in vitroculture conditions and associated anomalies in plants. Acta Biologica Cracoviensia Series Botanica 57(2):9-28. https://doi.org/10.1515/abcsb-2015-0026

Isah T (2015b). Rethinking Ginkgo biloba L.: medicinal uses and conservation. Pharmacognosy Reviews 9(18):140. https://doi.org/ 10.4103/0973-7847.162137

Isah T (2016). Induction of somatic embryogenesis in woody plants. Acta Physiologiae Plantarum 38:118. https://doi.org/10.1007/s11738-016-2134-6

Isah T (2017). Production of camptothecin in the elicited callus cultures of Nothapodytes nimmoniana (J. Graham) Mabberly. Chemical Papers 71(6):1091-1106. https://doi.org/10.1007/s11696-016-0056-9

Isah T, Mujib A (2013). In vitro plant regeneration of coffee senna (Senna occidentalis) from hypocotyl-derived callus. Acta Biologica Cracoviensia Series Botanica 55(2):120-25. https://doi.org/10.2478/abcsb-2013

Isah T, Mujib A (2015). Enhanced in vitroseedling recovery in Nothapodytes nimmoniana. British Biotechnology Journal 6(1):2231-2927. https://doi.org/10.9734/BBJ/2015/15368

Isah T, Mujib A (2015b). In vitro propagation and camptothecin production in Nothapodytes nimmoniana. Plant Cell, Tissue and Organ Culture 121(1):1-10. https://doi.org/10.1007/s11240-014-0683-1

Isah T, Mujib A (2015c). Camptothecin from Nothapodytes nimmoniana: review on biotechnology applications. Acta Physiologiae Plantarum 37:106. https://doi.org/10.1007/s11738-015-1854-3

Isah T, Umar S (2018). Influencing in vitroclonal propagation of Chonemorpha fragrans (moon) Alston by culture media strength, plant growth regulators, carbon source and photoperiodic incubation. Journal of Forestry Research 31:27-43. https://doi.org/10.1007/s11676-018-0794-3 
Isah T, Umar S (2019). Proteome study of embryogenic competence acquisition in the callus cultures of Nothapodytes nimmoniana (J. Graham) Mabberly. Acta Physiologiae Plantarum 41:96. https://doi.org/10.1007/s11738-0192896-8

Isah T, Umar S, Mujib A, Sharma MP, Rajasekharan PE, Zafar N, Frukh A (2018). Secondary metabolism of pharmaceuticals in the plant in vitro cultures: strategies, approaches, and limitations to achieving higher yield. Plant Cell, Tissue and Organ Culture 132(2):239-265. https://doi.org/10.1007/s11240-017-1332-2

Isah T (2019). Proteome study of somatic embryogenesis in Nothapodytes nimmoniana(J. Graham) Mabberly. 3 Biotech 9(4):119. https://doi.org/10.1007/s13205-019-1637-4

Jaleel CA, Gopi R, Gomathinayagam M, Panneerselvam R (2009). Traditional and non-traditional plant growth regulators alter phytochemical constituents in Catharanthus roseus. Process Biochemistry 44(2):205-209. https://doi.org/10.1016/j.procbio.2008.10.012

Kai G, Wu C, Gen L, Zhang L, Cui L, Ni X (2015). Biosynthesis and biotechnological production of anti-cancer drug Camptothecin. Phytochemistry Reviews 14(3):525-539. https://doi.org/10.1007/s11101-015-9405-5

Karwasara VS, Dixit VK (2013). Culture medium optimization for camptothecin production in the cell suspension cultures of Nothapodytes nimmoniana (J. Graham) Mabberley. Plant Biotechnology Reports 7(3):357-369. https://doi.org/10.1007/s11816-012-0270-Z

Kedari P, Malpathak NP (2014). Hairy cultures of Chonemorpha fragrans (Moon) Alston.: a potential plant for camptothecin production. Indian Journal of Biotechnology 13(2):231-235.

Kedari P, Malpathak NP (2016). Screening of Chonemorpha fragrans bioactive extracts for cytotoxicity potential and inhibition studies of key enzymes involved in replication. Pharmacognosy Magazine 12(46):297. https://doi.org/10.4103/0973-1296.185708

Kehie M, Kumaria S, Tandon P (2012). In vitro plantlet regeneration from nodal segments and shoot-tips of Capsicum chinense Jacq. cv. Naga King Chili. 3 Biotech 2(1):31-35. https://doi.org/10.1007/s13205-011-0025-5

Khan S, Karnat NM, Shankar D (2005). India's foundation for the revitalization of local health traditions. Pioneering In Situ conservation strategies for medicinal plants and local cultures. Herbalgram 68:34-48.

Kulkarni AV, Malpathak NP (2006). Micropropagation of Chonemorpha fragrans (moon) Alston: an endangered medicinal plant. Indian Drugs Bombay 43(12):1001.

Kulkarni AV, Patwardhan AA, Lele U, Malpathak NP (2010). Production of camptothecin in cultures of Chonemorpha grandiflora. Pharmacognosy Research 2(5):296-299. https://doi.org/10.4103/0974-8490.72327

Li Z, Liu Z (2003). Effects of benzyladenine and naphthalene acetic acid on growth and camptothecin accumulation in Camptotheca acuminata seedlings. Journal Plant Growth Regulation 22(3):205-216. https://doi.org/10.1007/s00344-003-0015-X

Liu Z, Adams J (1996). Camptothecin yield and distribution within Camptotheca acuminata trees cultivated in Louisiana. Canadian Journal of Botany 74(3):360-365. https://doi.org/10.1139/b96-045

Malik S, Zia M, Chaudhary MF (2007). In vitro plant regeneration from direct and indirect organogenesis of Momordica $\begin{array}{llll}\text { charantia. Pakistan Journal of Biological Sciences 10(22):4118-4122. } & \text {. }\end{array}$ https://doi.org/10.3923/pjbs.2007.4118.4122

Malik SK, Chaudhury R, Rajwant KK (2005). Rapid in vitro multiplication and conservation of Garcinia indica: a tropical medicinal tree species. Scientia Horticulturae 106(4):539-553. https://doi.org/10.1016/j.scienta.2005.05.002

Miao Y, Zhu Z, Guo Q, Yang X-H, Liu L, Sun Y, Wang C (2016). Dynamic changes in carbohydrate metabolism and endogenous hormones during Tulipa edulis stolon development into a new bulb. Journal of Plant Biology 59(2):121-132. https://doi.org/10.1007/s12374-016-0456-y

Mingzhang A, Jing W, Yue S, Wentao G, Longjiang Y (2011). Camptothecin distribution and content in Nothapodytes nimmoniana. Natural Product Communications 6(2):197-200. https://doi.org/10.1177/1934578X1100600210

Mujib A, Tonk D, Gulzar B, Maqsood M, Ali M (2020). Quantification of taxol by high-performance thin layer chromatography in Taxus wallichiana callus cultivated in vitro. Journal of Biotechnology, Computational Biology and Bionanotechnology 102(4):337-347. https://doi.org/10.5114/bta.2020.100425

Mulder-Krieger T, Verpoorte R, De Graaf YP, van Der Kreek M, Baerheim-Svendsen A (1982). The effects of plant growth regulators and culture conditions on the growth and the alkaloid content of callus cultures of Cinchona pubescens. Planta Medica 46(09):15-18. https://doi.org/10.1055/s-2007-970009

Murashige T, Skoog F (1962). A revised medium for rapid growth and bioassays with tobacco tissue cultures. Physiologia Plantarum 15(3):473-497. https://doi.org/10.1111/j.1399-3054.1962.tb08052.x 
Murthy HN, Lee EJ, Paek KY (2014). Production of secondary metabolites from cell and organ cultures: strategies and approaches for biomass improvement and metabolite accumulation. Plant Cell, Tissue and Organ Culture 118(1):1-16. https://doi.org/10.1007/s11240-014-0467-7

Ning GG, Bao MZ (2007). Plant regeneration from callus derived from immature embryo cotyledons of Prunus mume. HORTSCIENCE 42(3):744-747. https://doi.org/10.21273/HORTSCI.42.3.744

Nishitha K, Martin KP, Ligimol, Beegum AS, Madhusoodanan PV (2006). Micropropagation and encapsulation of medicinally important Chonemorpha grandiflora. In Vitro Cellular and Developmental Biology - Plant 42(5):385-388. https://doi.org/10.1079/IVP2006762

Qosim WA, Purwanto R, Wattimena GA (2013). Indirect organogenesis and histological analysis of Garcinia mangostana L. Asian Journal of Plant Science 12(6):279. https://doi.org/10.3923/ajps.2013.279.284

Raj D, Kokotkiewicz A, Drys A, Luczkiewicz M (2015). Effect of plant growth regulators on the accumulation of indolizidine alkaloids in Securinega suffruticosa callus cultures. Plant Cell, Tissue and Organ Culture 123(1):3945. https://doi.org/10.1007/s11240-015-0811-6

Rao K, Chodisetti B, Gandi S, Mangamoori LN, Giri A (2011). Direct and indirect organogenesis of Alpinia galanga and the phytochemical analysis. Applied Biochemistry and Biotechnology 165(5-6):1366-1378. https://doi.org/10.1007/s12010-011-9353-5

Rastogi RP, Mehrotra BN (1993). Compendium of Indian medicinal plants. Vol. II. New Delhi: CDRI, Publication Information Directorate, pp 178.

Roy A, Aich SS, Mukherjee S (2012). Differential responses to indirect organogenesis in rice cultivars. International Journal of Scientific and Research Publications 2(9):1-5.

Saini RK, Shetty NP, Giridhar P, Ravishankar GA (2012). Rapid in vitro regeneration method for Moringa oleifera and performance evaluation of field grown nutritionally enriched tissue cultured plants. 3 Biotech 2(3):187-192. https://doi.org/10.1007/s13205-012-0045-9

Sankar-Thomas YD, Lieberei R (2011). Camptothecin accumulation in various organ cultures of Camptotheca acuminata Decne grown in different culture systems. Plant Cell, Tissue and Organ Culture 106(3):445-454. https://doi.org/10.1007/s11240-011-9942-6

Sankepally SSR, Singh B (2016). Optimization of regeneration using differential growth regulators in indica rice cultivars. 3 Biotech 6(1):1-7. https://doi.org/10.1007/s13205-015-0343-0

Sanputawong S, Raknim T, Benchasri S (2015). Influence of different type of culture media and activated charcoal on callus induction and shoot multiplication of Cadamine lyrata. Journal of Agricultural Technology 11(8):16971704.

Skoog F, Miller CO (1957). Chemical regulation of growth and organ formation in plant tissues cultured in vitro. Symposia of the Society for Experimental Biology 11:118-130.

Sparzak-Stefanowska B, Krauze-Baranowska M, Hałasa R (2019). Influence of plant growth regulators on the shoot culture of Phyllanthus glaucus and accumulation of indolizidine alkaloids with evaluation of antimicrobial activity. Acta Physiologiae Plantarum 41:6. https://doi.org/10.1007/s11738-018-2796-3

Tomaszewska-Sowa M (2012). Effect of growth regulators and other components of culture medium on morphogenesis of sugar beet (Beta vulgaris L.) in unfertilized ovule in vitro cultures. Acta Agrobotanica 65(4). https://doi.org/10.5586/aa.2012.025

van Hengel AJ, Harkes MP, Wichers HJ, Hesselink PG, Buitelaar RM (1992). Characterization of callus formation and camptothecin production by cell lines of Camptotheca acuminata. Plant Cell, Tissue and Organ Culture 28(1):1118. https://doi.org/10.1007/BF00039910

Verma SK, Yucesan BB, Gurel S, Gurel E (2011). Indirect somatic embryogenesis and shoot organogenesis from cotyledonary leaf segments of Digitalis lamarckii Ivan., an endemic medicinal species. Turkish Journal of Biology 35(6):743-750. https://doi.org/10.3906/biy-1007-45

Verpoorte R, van der Heijden R, van Gulik WM, ten Hoopen HJG (1991). Plant biotechnology for the production of alkaloids: present status and prospects. In: Brossi A (Ed). TheAlkaloids: Chemistry and Pharmacology. Academic Press, San Diego, USA, pp 1-187. https://doi.org/10.1016/S0099-9598(08)60268-0

Vila SK, Rey HY, Mroginski LA (2004). Influence of genotype and explant source on indirect organogenesis by in vitro culture of leaves of Melia azedarach L. Biocell 28(1):35-42.

von Aderkas P, Bonga JM (2000). Influencing micropropagation and somatic embryogenesis in mature trees by manipulation of phase change, stress and culture environment. Tree Physiology 20(14):921-928. https://doi.org/10.1093/treephys/20.14.921 
Wamaitha MJ, Suwa K, Fukuda KI, Mii M, Daimon H, Mishiba KI (2010). Thidiazuron-induced rapid shoot regeneration via embryo-like structure formation from shoot tip-derived callus culture of sugarcane. Plant Biotechnology 27(4):365-368. https://doi.org/10.5511/plantbiotechnology.27.365

Yamazaki M, Asano T, Yamazaki Y, Sirikantaramas S, Sudo H, Saito K (2010). Biosynthetic system of camptothecin: an anticancer plant product. Pure and Applied Chemistry 82(1):213-218. https://doi.org/10.1351/PAC-CON-09$02-08$

Yoshikawa T, Furuya T (1985). Morphinan alkaloid production by tissues differentiated from cultured cells of Papaver somniferum (1). Planta Medica 51(2):110-113. https://doi.org.10.1055/s-2007-969421

Yuan W, Zhu P, Cheng K, Meng C, Ma L, Wu F, Zhu H (2007). Callus of Securinega suffruticosa, a cell line accumulates dextro Securinega alkaloids. Natural Products Research 21(3):234-242. https://doi.org/10.1080/14786410701189781

Zafar N, Mujib A, Ali M, Tonk D, Gulzar B, Malik MQ, Mamgain J, Sayeed R (2020). Cadmium chloride $\left(\mathrm{CdCl}_{2}\right)$ elicitation improves reserpine and ajmalicine yield in Rauvolfia serpentina as revealed by high-performance thinlayer chromatography (HPTLC). 3 Biotech 10:344. https://doi.org/10.1007/s13205-020-02339-6

Zambre M, Geerts P, Maquet A, Montagu MV, Dillen W, Angenon G (2001). Regeneration of fertile plants from callus in Phaseolus polyanthus. Annals of Botany 88(3):371-77. https://doi.org/10.1006/anbo.2001.1468

Zimmerman JL (1993). Somatic embryogenesis: a model for early development in higher plants. The Plant Cell 5(10):1411. https://doi.org/10.1105/tpc.5.10.1411
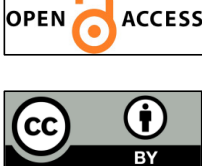

The journal offers free, immediate, and unrestricted access to peer-reviewed research and scholarly work. Users are allowed to read, download, copy, distribute, print, search, or link to the full texts of the articles, or use them for any other lawful purpose, without asking prior permission from the publisher or the author.

License - Articles published in Notulae Scientia Biologicae are Open-Access, distributed under the terms and conditions of the Creative Commons Attribution (CC BY 4.0) License.

(c) Articles by the authors; SHST, Cluj-Napoca, Romania. The journal allows the author(s) to hold the copyright/to retain publishing rights without restriction. 